\title{
From landscapes into geological history
}

Philip A. Allen

\section{Erosional and depositional landscapes are linked by the sediment-routing system. Observations over a wide range of timescales might show how these landscapes are translated into the narrative of geological history.}

Earth's landscape, shaped by the interplay between tectonics and climate, is a dynamic interface over which many biogeochemical cycles operate. The mass fluxes associated with the physical, biological and chemical processes acting across the landscape involve the transport of particulate sediment and solutes. Sediment is moved from source to sink — from the erosional engine of mountainous regions to its eventual deposition — by the sediment-routing system. The selective long-term preservation of elements of the sediment-routing system to produce the narrative of the geological record is dictated by processes operating in Earth's lithosphere. Making the connection between these two levels of enquiry - between the forces shaping present-day erosional and depositional landscapes and the long-term historical record - requires integration and ingenuity. If successful, we may indeed "see a world in a grain of sand" as the poet William Blake suggested.

The growing field of study of Earth surface processes is uniting the normally disparate disciplines of solid Earth geology, geomorphology and atmospheric and oceanographic sciences. Conference sessions are packed with contributions on Earth surface processes and new journal sections are devoted to it. These developments are not a result of a sudden conversion to an environmentalist agenda, but of a growing realization of the myriad of interactions, and the strength of the associated mass fluxes, that operate across the critical zone comprising Earth's surface. Understanding Earth surface processes therefore provides vital insights into how Earth functions as a system.

For Earth surface processes to be a vibrant new discipline, rather than a rebranding of conventional reductionist thinking, integration is required at different levels. One level is the integration of the physical, chemical and biological processes that shape Earth's surface and that drive its mass fluxes, investigated at the so-called human timescale - over the period for which we have historical records. The second level of integration is over larger spatial and temporal scales. Making the connections between these two levels is the exciting challenge that faces a wide range of natural scientists today.

\section{Sediment on the move}

Earth's surface is the critical interface across which the bulk of Earth's chemical and biological exchanges take place. Most biogeochemical cycles involve the transport of material by fluids either in dissolved form or as particles of sediment. In fact, more than 20 billion tonnes of particulate sediment is delivered to the ocean every year, representing an average rate of loss of 135 tonnes per annum from each square kilometre of Earth's surface ${ }^{1}$. About the same mass is washed into the oceans by rivers as solutes every year, thereby controlling the ocean's bulk geochemistry, nutrient loading and biological productivity. Ignoring anthropogenic effects, this annual delivery to the coastal ocean is controlled by variations in global topography, climate and rock type, which are ultimately dependent on plate tectonics.

In the deep geological past, there were periods of pronounced convergence and collision of tectonic plates, when they organized themselves into great supercontinents before splitting and dispersing. One such period of assembly about 680-530 million years ago produced the great supercontinent known as Gondwanaland. Erosion of the tectonic edifice caused by this amalgamation, which stretched for $10,000 \mathrm{~km}$ and was $1,000 \mathrm{~km}$ wide, resulted in the deposition of immense amounts of sand on the adjacent continental margins and in the deep sea ${ }^{2}$. The eroded material was equivalent to the blanketing of all of North America with a layer of sediment $10 \mathrm{~km}$ thick - an extraordinary image of the vigour of mass fluxes associated with Earth surface processes.

\section{The erosional engine of mountain landscapes}

Sites of plate collision are typified by high mountains that act as the engine for mass fluxes of sediment over Earth's surface. The topography of mountains forms in the face of a relentless attack by erosion, which carves deep valleys into tectonically uplifting bedrock. Because erosion depends strongly on climatic factors, a goal of geoscience has been to decipher the distinctive imprint of climatic variations on mountainous landscapes. Intuitively, this seems straightforward enough. But it is not, as the problem is complicated by an issue that bedevils (or enriches, depending on your standpoint) a great deal of the discipline of Earth surface processes - the different temporal resolution of two interacting sets of processes: in this case tectonic fluxes and climatically driven erosion. A challenge for the future is to make progress in discovering the governing equations for erosion and resolving their time dependence.

The tectonics of mountain belts acts like a juggernaut: changes in tectonic conditions, such as in the direction or speed of relative motion of two colliding plates, are transferred very slowly to the deforming zone between them and to its surface topography. The time for the mountain belt to adjust to the new tectonic conditions may be several millions of years ${ }^{3}$. Climate, by contrast, is changeable and fickle. By the time the topographic surface has noticed that there are stirrings deep in the mountain belt, the climate may have changed along the roller-coaster of cold to warm, wet to arid many times over, as is well known from the approximately 100,000year climatic periodicity of the late Pleistocene epoch. As a result, it is difficult to estimate the long-term release of particulate sediment from the erosional engine of mountains.

\section{Sediment-routing systems from source to sink}

One can imagine tracking the trajectory of a single grain of sand from its source in mountain headwaters to its sink in a river flood plain, delta or the deep sea (Fig. 1). Each grain would have a different trajectory and a different time in transit. The integration of a multiplicity of such trajectories defines a sediment-routing system ${ }^{4}$, and an integration of the different transit times, were it possible, would provide information on the ability of the routing system to buffer incoming sediment flux signals. In other words, the sediment flux signal from the contributing upland river catchment is likely to be transformed, phase-shifted and lagged by the internal dynamics of the routing system. If this is the case, how can we possibly decipher the forcing mechanisms for a particular record in deposited sediment without knowing how it has been transformed by the internal dynamics of the sediment-routing system? We are right to be suspicious of oversimplistic interpretation of the 'structure' found in the large number of time-series records that geology throws up - for 
instance, the mass accumulation rate of land-derived sediment in the ocean, or the packaging of genetic units of sedimentary rock. If the buffering timescale is greater than a million years for large river systems ${ }^{5,6}$, incoming sediment flux signals might be unrecognizable by the time they are propagated into the ocean.

Ideally, we would know all of the physical and chemical processes governing the sediment-routing system. This would be enormously gratifying in trying to understand how sediment-routing systems function generically, but we would immediately run into a fundamental problem: the long result of time. Time transforms sediment-routing systems into geology, and like history, selectively samples from the events that actually happened to create a narrative of what is recorded. Progress in understanding modern sediment-routing systems now leaves us poised to answer the important question: how do we simultaneously use the modern to generate the time-integrated ancient, and 'invert' the ancient to reveal the forcing mechanisms for change in the past?

\section{A world in a grain of sand}

A growth area in the Earth sciences is the tracking of sediment from source to sink. We naturally ask, when picking up a handful of beach sand, 'where does this come from'? This question of origins is the science of provenance.

In the past, provenance analysis was centred on the general mineralogical properties of sand and sandstone samples, and on the specific content of distinctive heavy minerals. Heavy minerals, in particular, acted as fingerprints for source areas and so could be used forensically to reconstruct the parent rocks in eroding source regions. Now, we use a battery of geochemical methods. But no matter how well we make this match between erosional source area and depositional sink, provenance studies cannot help us fully understand the dynamics of the sedimentrouting system that conveyed it from source to sink. It is rather like being present at the birth of a baby and the funeral of the man, but missing out on the life story. To understand the life story requires insights into the functioning of sediment-routing systems geomorphically under tectonic and climatic forcing.

\section{Landscape-evolution models}

A landscape-evolution model seeks to produce topography numerically in terms of the forcing mechanisms of climate and tectonics. Success is generally gauged by whether the resulting numerical landscape looks 'realistic'. The weakness is that the simulation of 'realistic' landscapes cannot be said to represent adequate model testing and validation, because the attainment of realism is conditional on the use of exponents and coefficients in the model equations for local erosion or deposition for which there may be weak independent support. These model equations are not like the governing equations of physics, but calibrated bulk parameterizations of observations. The issue of the extrapolation of local hydraulics or sediment dynamics to larger spatial scales and longer timescales is the classic problem of upscaling.

Let us take the example of the effects of cyclic glaciation, a mode of response to cyclic climate changes that Earth has experienced in the past few million years (see page 284). To build a numerical landscape-evolution model for times of glaciation we would need to know the sliding velocity of ice by solution of a chosen ice-dynamics equation, a proportionality constant in the ice-erosion equation that depends on the underlying rock type, a rheological law relating ice deformation to local stress, a model for ice accumulation and ablation, and knowledge of the temperature at the base of the ice. This might work theoretically by making a large number of assumptions, but the resulting model would be impossible to use in a simulation of Quaternary landscapes. Why? Because the necessary parameter values to inform a long-term landscape model are not currently available, and perhaps never will be. This humbling realization does not denigrate the efforts of modellers working at the human timescale, but instead prompts us to think afresh about what is required for success with upscaled models.

It is not immediately obvious that the factors controlling a long-term response may be different from those controlling local processes. To

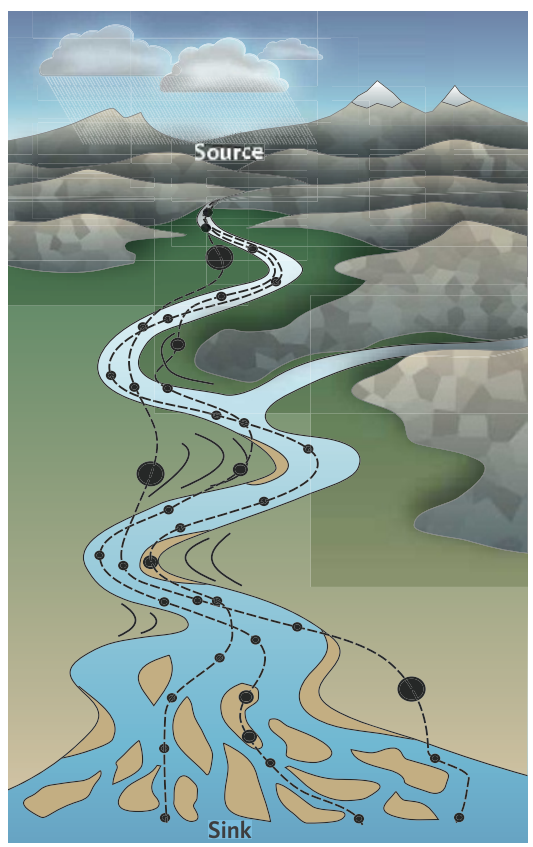

Figure 1 | The concept of a sediment-routing system. Sediment is transferred from a source region to a sink along trajectories shown by the dashed lines. Some trajectories involve short transit times with brief periods of storage in the sediment-routing system (small circles) (for example, on the river-channel bed), whereas others involve long transit times with prolonged periods of storage (large circles) (for example, in bars and especially on flood plains). Storage of sediment implies buffering of incoming sediment flux signals.

illustrate this point, the factors controlling the rate of accumulation of sediment in a river hinge on the local gradient in sediment-transport rate, which is controlled by local hydraulic variables, the range of sediment available and the details of the local topography of the channel, bars, banks and flood plain. The factors controlling the long-term accumulation of sediment, on the other hand, are related to the prolonged realms of subsidence of Earth's surface that are controlled by geophysical parameters associated with the crust and mantle. The two sets of parameters, each correct in their own setting, could hardly be more different.

One way out of this fix is to reformulate local transport equations into new ones that can be directly constrained by observational data - data that are found in the geological record. The upscaled model therefore does not rely on knowledge of local hydraulic or sediment dynamics information that it is impossible to acquire from the geological recorder of past geomorphic-sedimentary processes ${ }^{7}$.

Currently, long-term numerical landscape evolution models lack predictive power because their rate parameters are poorly constrained, commonly being derived from restricted conditions at the human timescale, and making it difficult to justify their extrapolations in time and space. Response times are poorly known, varied and complex ${ }^{8}$, and more data on long-term response are clearly required.

\section{Measuring rates with dates}

We need to make measurements of how Earth's surface has evolved over time spans long enough to capture the effects of both tectonics and climate, but what measurements should we make, and with what strategy? Earth scientists are faced with an imposing problem - to measure the erosional history of a landscape that no longer exists. But to do so is necessary if we are to understand the erosional engine that shapes Earth's surface. The study of the thermal history of rocks is the only method currently available to solve this problem.

Thermochronological techniques that capture the time-temperature trajectory of a rock ${ }^{9}$, such as apatite fission-track analysis and helium diffusion during $\mathrm{U}-\mathrm{Th}$ radioactive decay, provide vital information on cooling attributable to the rise to the surface of the Earth of a rock or mineral during erosion. The cooling history is recorded over geological timescales, dependent on the critical temperature and methodology used. When thermochronological methods are used in combination, they have the potential to provide invaluable constraints on long-term erosional history, but with certain caveats. At shallow depths, a crystal's time-temperature history is likely to be influenced by temperature variations caused by the irregular topography and variable temperature of Earth's surface. And even the helium-dating technique has a temporal resolution that seems 
clunky in relation to the fine scale of climate change. As a result, thermochronological methods, despite shedding much-needed light on long-term changes in the workings of the erosional engine, are unlikely to provide one-to-one connections between the high-frequency variations in climate that have typified the past few million years and landscape response. Other dating techniques, such as the use of nuclides produced during exposure of surfaces to cosmic radiation, offer a promising possibility of capturing this elusive landscape response to fine-scale climate change.

\section{Interactions and feedbacks}

The topography caused by the formation of mountains perturbs atmospheric circulation and steers the jet stream, thereby directly influencing regional and local climatic patterns, such as the distribution of precipitation. Strong gradients in precipitation patterns in turn dictate erosional behaviour as well as ecosystem type. This first-order feedback between tectonics and climate, seen as major spatial variations in precipitation between the wet windward side and the dry lee, is uncontroversial. What is more contentious is that the impact of tiny raindrops, through erosion, might cause the localization of the mighty forces of tectonic deformation; that is, erosion over a tectonically deforming crust (Fig. 2) encourages a flux of rock towards the site of surface erosion. Consequently, it has been proposed that heavy monsoon rains, and the resulting high erosion rates, might cause dormant faults to become active, that earthquakes might be concentrated near areas of high erosion, and that growing kilometre-scale folds in the fronts of mountain belts might amplify rapidly once they have broken through Earth's surface and experience erosion. Surprisingly, rates of tectonic deformation near the surface of Earth, and earthquake risk, might therefore be influenced by climate.

There is something of the chicken and egg in this debate, as there surely is in all strongly coupled systems. The same question was asked of the coupling between climate change and the surface uplift of mountain ranges in the past few million years ${ }^{10}$. Critical to answering the question of which triggers which is information on timing (so that connections can be made between different observational data sets) and information on system behaviour (so that the effects of internal dynamics can be understood and discriminated from external forcing such as climate change). As Jean Braun wrote ${ }^{11}$, "one must be reminded that the demonstration that a coupling between erosion and tectonics exists has so far been limited to the results of computer modelling of the system". So, what is known? At a basic level we know that high rates of deformation must be balanced by erosion, otherwise mountain ranges would continue to grow until they reached a height limit governed only by rock strength, or deep holes would appear in the core of mountain ranges in the absence of tectonic deformation. Observations from thermochronology, geochronology and sedimentation also make a close link in timing between erosional exhumation of mountain ranges and the fluxing of sediment onto fringing lowlands and ocean basins. Making sense of the more subtle couplings suggested by numerical models is now in the hands of observational geologists.

\section{The trap-door}

Because of the intricate coupling between tectonic deformation and surface sediment-routing systems, tectonic deformation preserves the sediment in constant flux over Earth's surface ${ }^{12}$. Consequently, the realms of subsidence driven by tectonic processe ${ }^{13}$ are the key to the transformation of erosional and depositional landscapes into the rock record of geological history.

Upland catchments release sediment into adjacent river systems or alluvial fans like a well-directed fire-hose, but the preservation of sediment in these systems depends on whether space is available for it to accumulate over long timescales. The amount of sediment preserved by this trapdoor effect is generally minute compared with the overlying flux, but over geological timescales it is this small fraction that builds the sedimentary layers of stratigraphy. It is also the clue to why tectonics, rather than factors linked to surface sediment fluxes, controls long-term sediment accumulation rates.

In areas such as the Basin and Range province of the southwestern United States, where the crust is extending by slip along steep normal

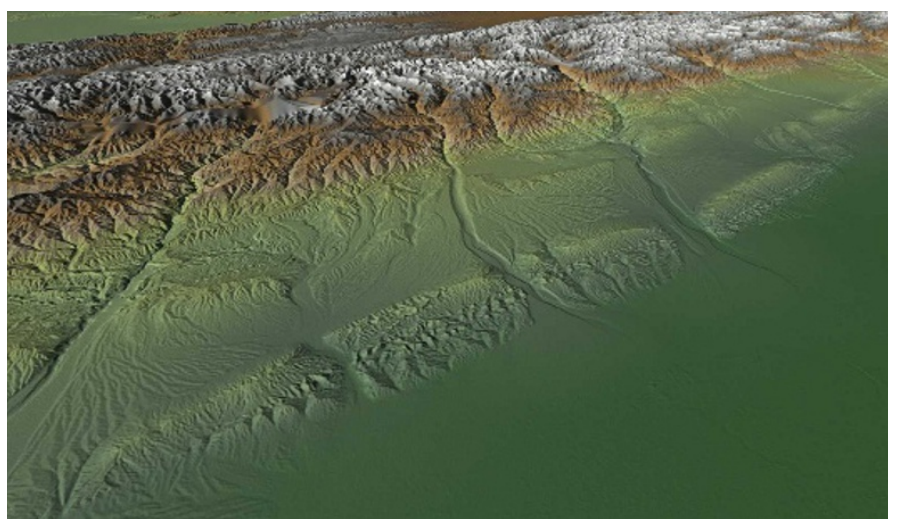

Figure 2| Interaction of erosion, sedimentation and surface deformation. Oblique-view digital elevation model of the Junggar region of central Asia, showing the interaction of erosion, sedimentation and deformation as the Tien Shan mountain range progrades tectonically into the sedimentary basin. The model is derived from 90-m resolution data from NASA's Shuttle Radar and Topography Mission. New tectonic folds are growing and being eroded in what was previously the low ground (green) of a sedimentary basin. (Image courtesy of K. Mueller, University of Colorado, Boulder.)

faults, it is believed that sediment fans, which accumulate against the uplifting mountain ranges, reflect the rate at which the faults slip by repeated earthquakes. Where the faults slip rapidly, the sediment fans are thought to have steep surface slopes and to show rapid down-system changes in particle size. The same effect can be seen in numerical models of much larger river systems. This fundamental control is invisible to the eyes of the observer standing on the surface. The critical parameter for a geomorphic trend is outside geomorphic space. There could hardly be a better advertisement for the integration of geomorphology and geology.

In essence, the burgeoning field of Earth surface processes requires a new conversation, so that the epic poem of Earth history can be better read and learned from. Figuratively, it requires atmospheric physicists to care about the tectonics of mountain ranges and for stratigraphers to care about fluvial hydrology. This new conversation will benefit from a close dovetailing of numerical modelling approaches with new observations relevant to a broad range of timescales.

Philip Allen is in the Department of Earth Science and Engineering, Imperial College, South Kensington Campus, London SW7 2AZ, UK.

Milliman, J. D. \& Meade, R. H. Worldwide delivery of river sediment to the oceans. J. Geol. 91, 1-21 (1983)

2. Squire, R. J., Campbell, I. H., Allen, C. M. \& Wilson, C. J. L. Did the Transgondwanan Supermountain trigger the explosive radiation of animals on Earth? Earth Planet. Sci. Lett. 250, 116-133 (2006).

3. Willett, S. D. Orogeny and orography: the effects of erosion on the structure of mountain belts, J. Geophys. Res. 104, 28957-28981 (1999).

4. Allen, P. A. Earth Surface Processes (Blackwell, Oxford, 1997)

5. Métivier, F. \& Gaudemer, Y. Stability of output fluxes of large rivers in South and East Asia during the last 2 million years: implications for floodplain processes. Basin Res. 11, 293-304 (1999)

6. Castelltort, S. \& Van Den Dreissche, J. How plausible are high-frequency sediment supplydriven cycles in the stratigraphic record? Sediment. Geol. 157, 3-13 (2003).

7. Fedele, J. J. \& Paola, C. Similarity solutions for fluvial sediment fining by selective deposition. J. Geophys. Res. Earth Surf. 112, F02038, doi: 10.1029/2005JF000409 (2007).

8. Allen, P. A. Striking a chord. Nature 434, 961 (2005).

9. Braun, J., van der Beek, P. \& Batt, G. Quantitative Thermochronology: Numerical Methods for the Interpretation of Thermochronological Data (Cambridge Univ. Press, Cambridge, 2006).

10. Molnar, P. \& England, P. Late Cenozoic uplift of mountain ranges and global climate change: chicken and egg? Nature 346, 29-34 (1990).

11. Braun, J. in Analogue and Numerical Modelling of Crustal-Scale Processes (eds Buiter, S. J. H. \& Schreurs, G.) Spec. Publ. Geol. Soc. Lond. 253, 307-325 (2006).

12. Leeder, M. R. Sedimentary basins: Tectonic recorders of sediment discharge from drainage catchments. Earth Surf. Process. Landforms 22, 229-237 (1997).

13. Allen, P. A. \& Allen, J. R. Basin Analysis: Principles and Applications 2nd edn (Blackwell, Oxford, 2005).

14. Malmon, D. V., Dunne, T. \& Reneau, S. L. Stochastic theory of particle trajectories through alluvial valley floors. J. Geol. 111, 525-542 (2003).

Author Information Reprints and permissions information is available at npg.nature.com/reprints. Correspondence should be addressed to the author (philip.allen@imperial.ac.uk). 